\title{
Aluno-docente: ressignificando saberes através da trajetória e percepção do estágio curricular supervisionado
}

\author{
Student-teacher: resigning knowledge through the path and perception of the supervised \\ curriculum internship
}

Estudiante-profesor: resignificando conocimientos a través de la trayectoria y percepción del internado curricular supervisado

\section{Resumo}

O Estágio Curricular Supervisionado na intenção de produzir conhecimento leva em consideração a teoria e a trajetória do aluno imerso nesta práxis. Este estudo foi pensado a partir do processo de trajetória pessoal e formação acadêmica do aluno em formação, chamado de estagiário nos espaços pedagógicos e que chamaremos de alunodocente. Este estudo objetiva conhecer a trajetória acadêmica e pessoal do aluno-docente e sua percepção frente ao Estágio Curricular Supervisionado no Curso de Formação de Professores para Educação Infantil e Anos Iniciais no sentido de (re)significar saberes e repensar práticas docentes na formação inicial. Trata-se de um estudo de abordagem qualitativa com a participação de 7 alunos concluintes do Curso de Formação de Professores de uma escola pública do interior do Rio Grande do Sul, sendo os dados coletados entre setembro e dezembro de 2020. A prática do alunodocente no percurso formativo foi sentida com dificuldades iniciais que deram origem a construção de uma prática sólida e reconhecida por estes alunos. Ressignificar saberes para este grupo de alunos-docentes faz parte da realidade do Estágio Curricular Supervisionado, onde sua vivência e experiência é construída. É no chão da escola que saberes e práticas são partilhadas e o conhecimento docente acontece.

Palavras-chave: Curso normal; Docência; Formação inicial; Ensino.

\begin{abstract}
The Supervised Curricular Internship with the intention of producing knowledge takes into account the theory and trajectory of the student immersed in this praxis. This study was designed from the process of personal trajectory and academic training of the student in training, called an intern in pedagogical spaces and that we will call studentprofessor. This study aims to understand the academic and personal trajectory of the student-professor and their perception of the Supervised Internship in the Teacher Training Course for Early Childhood Education and Early Years in order to (re)signify knowledge and rethink teaching practices in initial training. This is a study with a qualitative approach with the participation of 7 students graduating from the Teacher Training Course of a public school in the interior of Rio Grande do Sul, with data collected between September and December 2020. The practice of the student- teacher in the formative path was felt with initial difficulties that gave rise to the construction of a solid practice recognized by these students. Resigning knowledge to this group of student-teachers is part of the reality of the Supervised Curricular Internship, where their experience and experience is built. It is on the school floor that knowledge and practices are shared and teaching knowledge takes place.
\end{abstract}

Keywords: Normal course; Teaching; Initial formation; Teaching.

\section{Resumen}

El Internado Curricular Supervisado con la intención de producir conocimiento toma en cuenta la teoría y trayectoria del alumno inmerso en esta praxis. Este estudio fue diseñado a partir del proceso de trayectoria personal y formación 
académica del alumno en formación, denominado pasante en espacios pedagógicos y que llamaremos alumnoprofesor. Este estudio tiene como objetivo comprender la trayectoria académica y personal del alumno-docente y su percepción del Internado Supervisado en el Curso de Formación Docente de Educación Infantil y Primera Edad con el fin de (re) significar conocimientos y repensar las prácticas docentes en la formación inicial. Se trata de un estudio con enfoque cualitativo con la participación de 7 alumnos egresados del Curso de Formación Docente de una escuela pública del interior de Rio Grande do Sul, con datos recolectados entre septiembre y diciembre de 2020. La práctica del alumno-docente en el camino formativo se sintió con dificultades iniciales que dieron lugar a la construcción de una práctica sólida reconocida por estos estudiantes. Renunciar al conocimiento a este grupo de alumnos-docentes es parte de la realidad del Internado Curricular Supervisado, donde se construye su experiencia y vivencia. Es en el piso de la escuela donde se comparten conocimientos y prácticas y se lleva a cabo la enseñanza del conocimiento.

Palabras clave: Curso normal; Enseñando; Formación inicial; Enseñando.

\section{Introdução}

Educação, no sentido literal da palavra é "o ato de educar, de instruir, é polidez, disciplinamento" (Ferreira, 2004). No seu sentido mais amplo, "educação significa o meio em que os hábitos, costumes e valores de uma comunidade são transferidos de uma geração para a geração seguinte" (Zanten, 2011).

Partindo desse princípio, a escola é o espaço educacional responsável pelo conhecimento e que contribui com a sociedade para a formação de indivíduos capazes de produzir socialmente. Nesse contexto o professor ao ser relacionado com a escola é ao mesmo tempo, determinante e determinado, ou seja, "assim como seu modo de agir e de ser, recebem influências do ambiente escolar, ele também influencia este mesmo ambiente (Cunha, 1996)".

Pensar o Estágio Curricular Supervisionado como forma de produção de conhecimento levando em consideração a teoria e a trajetória do aluno imerso nesta práxis, no sentido de (re)significar saberes e práticas é sem dúvida uma tarefa desafiadora. Lima (2014) fala em seus estudos que "reconhece-se a dissociação entre o aprender e o fazer como uma questão determinante na concepção pedagógica, revelada pela dicotomia entre teoria e prática”, tema de extrema relevância para a educação.

A questão central deste estudo pode ser pensada a partir do processo de trajetória pessoal e formação acadêmica do aluno em formação, chamado de estagiário na maioria dos espaços pedagógicos e que aqui chamaremos de aluno- docente. Justificamos essa escolha pela análise da realidade deste aluno, que ao mesmo tempo em que é um estudante concluindo seu curso de formação, é um docente a frente de uma turma no Estágio Curricular Supervisionado-ECS ${ }^{1}$ com todas as responsabilidades inerentes a atuação docente.

Este estudo tem por objetivo conhecer a trajetória acadêmica e pessoal do aluno-docente e sua percepção frente ao Estágio Curricular Supervisionado no Curso de Formação de Professores para Educação Infantil e Anos Iniciais de uma Instituição da rede Pública de ensino do interior do Rio Grande do Sul, no sentido de (re)significar saberes e repensar práticas docentes na formação inicial.

\section{O estágio curricular supervisionado no contexto do curso normal}

O Estágio Curricular Supervisionado, além de desenvolver no aluno-docente uma consciência crítica e reflexiva sobre a docência, propicia uma mudança na realidade social deste aluno. No contexto da Educação Infantil e Anos Iniciais é fundamental a participação das crianças sendo eles os agentes de mudança descritos aqui, além de ser um momento singular de aprendizagem, tanto para quem ensina quanto para quem aprende.

\footnotetext{
${ }^{1}$ Será usado ao longo do texto a sigla ECS para fazer referência ao Estágio Curricular Supervisionado.
} 
De acordo com Oliveira e Silva (2020), há necessidade que "esse processo formativo ocorra de dentro para fora, ou seja, ele deve partir da realidade e demandas da comunidade escolar e não trazido por pessoas/profissionais fora daquele contexto" e isso inclui o aluno- docente.

Discutiremos aqui atividades referentes ao aluno-docente e suas implicações pessoais e profissionais no ECS no curso de Formação de Professores-Curso Normal e Aproveitamento de Estudos, ressaltando ações pedagógicas significativas. A concepção pedagógica sinaliza a centralidade das práticas sociais tendo origem e foco no processo de conhecimento da realidade, no diálogo como mediação de saberes e de conflitos transformando a realidade pela ação crítica dos próprios sujeitos. Nestas práticas sociais, os seres humanos produzem conhecimento, desenvolvem e consolidam sua concepção de mundo, conformam as consciências e viabilizam a convivência.

A prática social e o trabalho como princípio educativo, a fim de promover o compromisso de construir projetos de vida, individuais e coletivos, de sujeitos que apropriam da construção do conhecimento e desencadeiam as necessárias transformações da natureza e da sociedade, contribuindo para o resgate do processo de humanização baseado na ética, na justiça social e fraternidade (PPP, 2016, p. 17).

O referido Curso de Formação de Professores é apresentado em dois formatos: Nível Médio- Curso Normal e Pós Médio- Aproveitamento de Estudos.

O Ensino Médio - Curso Normal, como etapa final da Educação básica, tem por finalidade propiciar o desenvolvimento dos educandos, assegurando-lhe a formação comum indispensável para o exercício da cidadania e fornecerlhe meios para progredir no trabalho e em estudos posteriores, destacando a educação profissional voltada à formação de professores de educação Infantil e Anos Iniciais do Ensino Fundamental.

Entendemos que um Curso de Formação de Professores deve proporcionar a formação para a vida e para a convivência, no exercício cotidiano dos Direitos Humanos como forma de vida e organização social, política, econômica e cultural, além de oportunizar a formação de professores através da compreensão do que é aprender, de como se aprende e onde se aprende, considerando que contribuir conhecimento decorre da relação com o outro e com o objeto a ser conhecido, estabelecendo uma constante relação entre teoria e prática e possibilitar ao aluno o entendimento da infância, em seu processo social e histórico da criança na situação de sujeitos de direitos.

Já o Pós-Médio- Aproveitamento de Estudos visa desenvolver as capacidades cognitivas, afetivas, emocionais, corporais, éticas, estéticas, de inserção social e interação pessoal e conhecimentos pedagógicos, que favoreçam o exercício autônomo e responsável das funções docentes, estabelecendo a união entre teoria e prática pedagógica e a flexibilidade para adaptar-se às novas condições do mercado de trabalho.

O estágio curricular supervisionado compreende a prática educativa, os processos formativos e os aspectos que influenciam essa prática. Dessa forma, defende-se que a formação docente inicial seja abordada em um processo que privilegie a reflexão sobre a prática, uma reflexão que possibilite a construção de uma trajetória metodológica que seja edificada, de forma participativa com os envolvidos nos processos de ensino e aprendizagem, gerando novos saberes e reflexões sobre sua formação.

Pimenta (1997), aponta o estágio como "uma atividade que traz elementos da prática para ser objeto de reflexão, de discussão, e que propicia um conhecimento da realidade ao qual irão atuar. Ratificando essas palavras Nóvoa (2006) diz que "as práticas são investidas do ponto de vista teórico e metodológico, dando origem à construção de um conhecimento profissional docente". 
A construção da prática docente demanda uma série de questões complexas. Embora o conhecimento seja a base principal para o desenvolvimento profissional docente, o final do curso e o início das atividades de estágio requer esforço e dedicação por parte do aluno-docente, personagem central deste estudo.

A realização do Estágio pode ser esperada por grande maioria dos alunos concluintes, tornando-se um período repleto de anseios e expectativas. Reformular, aprender, aceitar e realinhar as ideias, a fim de conseguir desempenhar as atividades do ECS de maneira reflexiva acerca de sua ação é a desafio de todo aluno-docente que se aventura na prática docente inicial.

Para Shön (2000), "podemos refletir sobre a ação pensando retrospectivamente sobre o que fizemos de modo a descobrir como nosso ato de conhecer-na-ação pode ter contribuído para o resultado". A reflexão sobre a prática é uma premissa do ECS, porém é necessário que o aluno-docente tenha em mente que faz parte de todo o processo de formação e não apenas do período final de formação.

Inúmeros estudiosos na área apontam a necessidade/importância da reflexão sobre a prática no ECS, dentre eles Piconez. A autora destaca que:

A aproximação da realidade possibilitada pelo Estágio Supervisionado e a prática da reflexão sobre essa realidade têm se dado numa solidariedade que se propaga para os demais componentes curriculares do curso, apesar de continuar sendo um mecanismo de ajuste legal usado para solucionar ou acobertar a defasagem entre conhecimentos teóricos e atividade prática (Piconez, 1991, p. 23).

Por outro lado, para que o ECS faça sentido de fato é importante existir uma conexão entre teoria e prática. Essa articulação de diferentes posturas educacionais ressalta o componente prático aliado com o conhecimento mostrando ao alunodocente competências relacionadas a prática e os campos de atuação profissional.

\section{(Re)significando saberes através da prática docente}

É sabido que o ECS é parte essencial do processo de aprendizagem da docência trazendo ao aluno-docente uma colaboração necessária a sua formação. Além de oportunizar situações reais de aprendizagem, vivenciar experiências práticas de aprendizagem da docência permite que o aluno-docente (re)pense e (re)signifique sua prática, tomando o protagonismo que lhe é inerente, buscando desenvolver ações que de fato o instrumentalize com habilidades e competências profissionais, articulando teoria e prática e construindo conhecimento em meio a prática docente.

Ao término do processo de formação inicial quando o aluno-docente encaminha-se para o Estágio Curricular respaldado em práticas profissionais e na sua trajetória docente e em Políticas Públicas de Educação que amparam sua prática.

Ao falar em Políticas Públicas referentes ao ECS a Lei $N^{\circ}$ 11.788/08, que dispõe sobre os estágios de estudantes merece destaque por sua importância uma vez que consolida e ampara perante a legislação educacional a prática docente no ECS. O artigo $1^{\circ}$ dessa Lei aponta que

Estágio é ato educativo escolar supervisionado, desenvolvido no ambiente de trabalho, que visa à preparação para o trabalho produtivo de educandos que estejam frequentando o ensino regular em instituições de educação superior, de educação profissional, de ensino médio, da educação especial e dos anos finais do ensino fundamental, na modalidade profissional da educação de jovens e adultos (Brasil, 2008, p. 01)

Associada à ela, a Lei de Diretrizes e Bases da Educação- LDB- Lei No 9394/96/20 juntamente com os Parâmetros Curriculares Nacionais-PCNs reforçam o itinerário formativo tendo como finalidade o contato com a prática, desenvolvendo no estudante competências próprias da atividade profissional.

Nesse intuito Lima aponta: 
O ECS traz uma colaboração essencial à formação do aluno como um momento específico de sua aprendizagem. Espera-se que o estudante possa identificar pontos favoráveis e desfavoráveis no campo da prática, exercendo a capacidade de reflexão sobre a ação profissional e de visão crítica sobre as relações existentes no campo institucional, apoiado na supervisão enquanto processo dinâmico e criativo, tendo em vista possibilitar a elaboração de novos conhecimentos (2014).

Segundo Viroli (2021), “as licenciaturas devem inserir seus estagiários na educação básica públicas ou particulares com a pretensão de potencializar a prática pedagógica estabelecendo a relação entre teoria e prática".

A compreensão entre o saber e o saber-fazer das dimensões teórica e da vivência da prática, apontando para um aprendizado dinâmico e progressivo, acompanhando e sendo acompanhado por profissionais atuantes na educação, faz o ECS além de uma percepção de valores, significar e (re)significar saberes em um projeto gradativo e sistematicamente pensado na ação formativa.

(Re)significar saberes nesse contexto nas palavras Marran (2004), "requer movimento, interação e a dialogicidade necessária para aprofundamento do fazer reflexivo e refletido". Essa autora pondera que o saber-fazer não se reduz ao conhecimento de um punhado de técnicas e metodologias de ensino, mas "com o que fazer para a promoção da qualidade da intervenção, resultando numa aprendizagem significativa (2004) e um saber significativo para o aluno-docente

Se um dos objetivos do Estágio Curricular for acenar para a formação de "profissionais reflexivos" como aponta Aranha (2006), seguida por inúmeros autores que defendem essa - Shön (2000) e Alarcão (2011). Para Alarcão, a noção de professor reflexivo baseia-se na consciência da capacidade de pensamento e reflexão que caracteriza o ser humano como criativo e não como reprodutor de ideias e práticas. Aranha conclui corroborando com a noção do profissional reflexivo como "uma pessoa que, nas situações profissionais tantas vezes incertas e imprevistas, atua de forma inteligente e flexível, situada e reativa (2006)".

Se o ECS puder despertar no aluno-docente o reconhecimento de que a formação oferecida em sala de aula em cursos de formação inicial por si só não seria suficiente para preparar professores capazes de resignificar saberes através da prática, mas que se faz necessário para a contextualização de uma formação emancipatória e libertadora, interagindo com a realidade profissional de sua escolha, dando liberdade e segurança para (re)significar saberes através da prática docente.

\section{Metodologia}

O presente estudo segue uma abordagem qualitativa (Bauer e Gaskell, 2008) e contou com a participação de 7 alunos concluintes do Curso de Formação de Professores para Educação Infantil e Anos Iniciais de uma escola pública do interior do Rio Grande do Sul. A justificativa para a amostra total de 7 alunos, refere-se ao número de alunos que iniciaram e realizaram o estágio entre setembro e dezembro de 2020, período de coleta dos dados.

O educandário aqui descrito é uma escola da rede estadual do Rio Grande do Sul localizada na zona urbana central que atende alunos de todas as classes sociais, com predominância de alunos de classes menos favorecidas oferecendo desde a Educação Infantil ao Ensino Médio. O IDEB da escola é 6.7 (INEP, 2019).

Os dados foram coletados entre setembro e dezembro de 2020 utilizando roteiro de entrevista semiestruturada com questões abertas organizado em 3 Eixos Temáticos assim dispostos:

Eixo 1: Trajetória Docente;

Eixo 2: Percepções do Estágio Curricular Supervisionado;

Eixo 3: Saberes relativos à Docência.

Com Eixo 1 pretende-se discutir as trajetórias do aluno-docente pensando a respeito da sua relação com a docência e com a sua opção por esta área. O segundo Eixo relaciona o futuro professor com seu exercício profissional, suas percepções 
das demandas profissionais durante o Estágio. Já o terceiro Eixo remete aos sentidos e saberes da docência relacionando a relação que o aluno-docente faz com o "ser professor" no ECS.

As entrevistas foram realizadas via Google Meet que conforme Termo de Consentimento Livre e Esclarecido, foram gravadas e transcritas. Para tratamentos dos dados utilizou-se Análise de Conteúdo tendo como referencial Bardin (2016).

A partir desse referencial as categorias de análise dos dados foram elencadas da seguinte forma: $\mathrm{O}$ aluno-Docente; Percepções da Docência; Saberes através da Prática.

Para manter o anonimato e a privacidade dos entrevistados, cada aluno- docentes participantes desse estudo foi identificado como AD1, AD2 (Aluno Docente 1,2) e assim sucessivamente.

\section{Resultados e Discussão}

O processo de análise dos dados na tentativa de entender a trajetória e percepção do aluno-docente no contexto do Estágio Curricular Supervisionado nos permite aqui elencar as seguintes categorias de análise: Trajetória Docente; Percepção da Docência; Saberes através da Prática.

Quando questionados sobre sua trajetória docente e de que maneira se interessou pela docência os alunos-docentes entrevistados relataram que de alguma forma tinham um sonho em ser professor e ao longo de sua trajetória acadêmica tiveram professores inspiradores que despertaram neles o interesse pela docência. Outros revelam a identificação com a docência ao iniciar o ECS, como releva a fala que segue:

"E quando eu fui para a escola pela primeira vez como estagiária descobri que ali era o meu chão, lembrei de todos os professores que eu tive (AD1)".

Kenski faz um alerta sobre esse comportamento no sentido de que ficar ligado a modelos docentes antigos pode prejudicar o aluno docente na construção de sua própria identidade docente. A autora afirma que

Ficar de certa forma atrelado a modelos retirados de exemplos de prática docente de professores que marcaram sua vivência escolar (nem sempre positiva) e passar a considerá-los "sua identidade", tornando-se personagem que interpreta um papel de professor. Dessa forma, ele não consegue dar o "salto", estabelecer seu espaço crítico, e criar, através de identificações e separações, a sua própria identidade de mestre (Kenski, 2001).

Ao citar a trajetória docente vários alunos informaram os desafios do percurso formativo até chegar ao ECS e descrevem com suas palavras o que de fato à docência significa. Isso fica visivelmente aflorado em algumas falas.

"Foi muito dificil chegar até aqui. A docência para mim hoje é uma prática necessária ao meu coração e a minha realidade. Escutar uma criança alimenta minha alma. Eles (alunos) nos passam tanto carinho que ser professora para mim é ser alguém que acredita num mundo melhor e o estágio me proporcionou isso (AD2)".

"O estágio é desafiar a criança todo dia com o teu trabalho e ver o retorno desse trabalho. Isso faz o coração de uma professora pular de alegria. É o reconhecimento, o retorno por parte do aluno. Não tem dinheiro que pague (AD1)”.

"O estágio é uma janela ampla cheia de conhecimento e de mudança que transforma nosso olhar em um novo olhar trazendo sentido e significado ao mundo e a nossa realidade como professora. A docência transforma (AD3)”.

A prática docente é marcada por inúmeros momentos construtivos. Marques et. al. (2019) corrobora com a fala dos alunos-docentes ao falar que ao iniciar a carreira do magistério muitas inquietações e situações inesperadas ocorrem e, por 
esses momentos, os saberes pedagógicos podem não ser suficientes e as reações dos professores podem ser as mais diversas possíveis.

Quando perguntados sobre o que a docência significa para cada um dos alunos-docentes, percebemos que as expectativas depositadas no curso de formação de professores e por conseguinte no Estágio Curricular Supervisionado é muito alta. As falas confirmam:

"A docência significa para mim a liberdade de me reinventar e me superar na vida profissional e pessoal (AD5)";

"A alegria de ver o desenvolvimento e cada passo meu e das crianças (AD7)";

"Significa uma realização pessoal (AD2)";

Já quando questionados sobre as aspirações de vida com relação à Docência e ao Curso Normal vemos os sonhos depositados no ECS e consequentemente na conclusão do curso no que diz respeito a mudança de vida, visto a realidade do alunado da escola descrita aqui.

"É seguir em frente e partir para uma graduação na área da Educação (AD4)”;

"Em ver o resultado positivo de todo que transmitimos os rostinhos das crianças quando aprendem coisas novas, e o reconhecimento das pessoas a o ver nosso trabalho. Me formar, trabalhar e ser feliz com a profissão que escolhi (AD7)";

Piconez (1991) aponta que "o Estágio e a Prática de Ensino trouxe-nos uma sensação gratificante de havermos iniciado a realização de alguma coisa que nos envolveu, nos interessou e nos fez crescer.

Nas palavras de Kulcsar (1991), "o estágio deve proporcionar o engajamento do estagiário na realidade, para que possa perceber os desafios que a carreira do magistério lhe oferecerá e possa, assim, refletir maduramente sobre a profissão que vai assumir".

Sintetizando as falas dos alunos-docentes participantes deste estudo percebemos que muitos alunos trouxeram à tona durante as entrevistas seu imaginário infantil e a representação que o professor tem na sua vida. Muitos citaram professores inspiradores e as expectativas depositadas no Curso de Formação de Professores no que diz respeito a melhoria de vida.

Sobre o ECS os alunos-docentes relataram também que o Estágio em si permitiu os recursos necessários a vivência da docência na prática.

Com a palavras, os alunos:

"Minha prática docente foi concluída com êxito, de forma positiva em relação aos pais e alunos. Meu planejamento contemplou a matriz curricular, tendo a aprovação da coordenadora, supervisora e assessora da turma, os alunos eram bem participativos, a frequência era boa e as avaliações ocorreram de acordo com a participação dos alunos nas atividades (AE2)”.

"A prática pedagógica no estágio me trouxe uma nova visão sobre o que é educação e o quão fundamental é saber oportunizar e desenvolver habilidade partindo da prática diária dentro da sala de aula. Perceber que esses momentos são propícios ao professor que pode oportunizar ao aluno e si próprio novos desafios (AE3)”. 
Marques; Neto; Brancher (2019) apontam que dentre os inúmeros saberes que compõem o repertório docente, "o estagiário, em sua formação inicial, lida com o árduo desafio de equilibrar os diferentes saberes disciplinares e das ciências da educação juntamente com o desenvolvimento do saber experiencial".

Quando questionados sobre qual o sentido e percepções da docência ao realizar o ECS nota-se que o aluno-docente participante do estudo percebe a importância do Estagio Curricular Supervisionado para sua formação, ao mesmo tempo em que percebe a sua importância enquanto futuro professor de Educação Infantil e Anos Iniciais, fazendo planos para a profissão que escolheu.

"O real sentido da docência é a importância que ela carrega para a aprendizagem dos alunos, o professor é de suma importância para que esse conhecimento seja assimilado pelo aluno, vai além de só transmitir o conhecimento e sim fazer que esse conhecimento seja vivido pelos alunos (AE6)".

"É terminar o curso e poder fazer o bem a todos que precisam de ajuda, e principalmente conseguir chegar até minhas metas finais me formar e trabalhar na área que eu escolhi (AE7)”.

"Estar sempre em busca do saber e da formação continuada, qualificando e aprimorando os conhecimentos adquiridos. É um amor pela docência que só aumenta, não há prazer e alegria maior do que estar numa sala de aula. A cada dia que passa só aumenta o desejo de realizar o meu sonho de me tornar professora (AE3)".

Sendo assim, Bolzan descreve que o ECS como um processo assim como toda formação em si. Ela cita que talvez nunca estejamos prontos e que o processo formativo que se fecha com a conclusão do Estágio Curricular Supervisionado seja reaberto a cada formação continuada.

O processo de constituição desse conhecimento implica na reorganização contínua dos saberes pedagógicos, teóricos e práticos, da organização das estratégias de ensino, das atividades de estudo e das rotinas de trabalho dos docentes, onde o novo se elabora a partir do velho, mediante ajustes desses sistemas (Bolzan, 2002).

Todos os alunos são unânimes quando se referem aprendizagem e saberes através da prática, reconhecendo o ECS como espaço vivencial e necessário a práxis docente, onde tempo e espaço podem ser pensados para (re)significar saberes e práticas, diminuindo a distância entre teoria e prática, vislumbrando a realidade profissional.

"O estágio nos prepara 100\% para desenvolver um trabalho prático e lúdico, onde a aprendizagem não se limita a somente um método e sim a uma prática que envolve o uso de vários recursos como jogos, brincadeiras, contação de histórias, etc.(AD2)".

"O estágio nos coloca dentro da sala de aula onde vivenciamos a experiência de nos sentirmos como professores pois temos que planejar e identificar as dificuldades dos alunos, mas ao mesmo tempo temos a ajuda de professores formados para nos auxiliar em nossas dúvidas e dificuldades (AD5)”.

"O estágio proporciona sim recursos para a aprendizagem da docência por que você pode colocar em prática o que foi aprendido em sala de aula e também aprimorar o que você aprendeu durante o curso (AD6)".

O Estágio Supervisionado constitui uma das partes de substancial importância da formação inicial dos professores. Segundo Alves (2020), "o modo de como o professor desenvolve suas habilidades/competências na realidade em que está inserido, referendando assim a necessidade de refletir sobre sua formação". 
Por fim destaca-se a necessidade de proporcionar momentos em que o aluno-docente possa (re)pensar sua prática no sentido de (re)significar saberes, tornando-a reflexiva e formativa.

\section{Considerações Finais}

Após análise dos dados, é possível tecer considerações acerca da trajetória acadêmica e pessoal do aluno-docente e suas percepções frente ao Estágio Curricular Supervisionado (re)significando saberes e entendendo que o percurso pessoal permeia o percurso acadêmico.

A evolução e amadurecimento pessoal e profissional experimentado no ECS permitiu analisar a trajetória de formação acadêmico-pessoal e a percepção sobre a docência e o processo de formação inicial no curso de formação de professores descrito aqui.

As percepções com relação ao Estágio Curricular Supervisionado são inerentes a condição de aluno-docente que considera essa fase de extrema importância para o processo de formação docente visualizando o ECS como parte decisiva da aprendizagem da docência onde os saberes podem ser aprendidos, reformulados e (re)significados à medida em que a identidade docente vai se consolidando.

A prática docente no Estágio Curricular Supervisionado foi sentida pelos alunos como período de muito esforço e satisfação por parte do grupo de estagiários aqui descritos como aluno-docente conseguindo construir uma prática docente durante o Ensino Curricular Supervisionado como forma de significação de saberes e práticas.

A prática do aluno-docente que começou e concluiu seu percurso formativo docente no ECS foi sentida com dificuldades iniciais que deram origem a construção de uma prática sólida e reconhecida por estes alunos.

Ressignificar saberes para este grupo de alunos-docentes faz parte da realidade do Estágio Curricular Supervisionado, onde sua vivência e experiência é construída. É no chão da escola que saberes e práticas são partilhadas e o conhecimento docente acontece.

Destaca-se a importância de estudos relativos a temática descrita aqui a fim de contribuir para que o Estágio Curricular Supervisionado consiga de fato ressignificar saberes fazendo com que o aluno docente possa valer-se desse aprendizado para dar sentido a sua prática docente, discutindo e difundindo conhecimentos acerca do ECS e da formação inicial.

\section{Referências}

Alves, A. P. C. \& Brancher, V. R. (2020). Um olhar sobre a docência do professor não licenciado na Educação Profissional e Tecnológica. https://www.revistas.unijui.edu.br/index.php/contextoeducacao/article/view/10322.

Alarcão, I. (2011). Professores reflexivos em uma escola reflexiva. Cortez.

Aranha, M. L. A. (2006). Filosofia da Educação. (3 ed. rev. e ampl.) Moderna.

BArdin, L. (2016). Análise de Conteúdo (30ª . ed.). Lisboa: Portugal.

Bauer, M. W.\& Gaskell, G. (2008). Pesquisa Qualitativa com texto, imagem e som. Vozes.

Bolzan, D. P. V. (2002). Formação de professores: compartilhando e reconstruindo conhecimentos. Mediação.

BRASIL, Portaria No 356/2020. Disponível em: http://www.in.gov.br/en/web/dou/-/portaria-n-356-de-11-de-marco-de-2020-247538346. Data do Acesso: 20. Jun. 2020.

BRASIL. (2020). Portaria No 343/2020. http://www.in.gov.br/en/web/dou/-/portaria-n-343-de-17-de-marco-de-2020-248564376.

Buriolla, M. A. F. (1995). Estágio Supervisionado. Cortez.

Cunha. M. I. (1992). O bom professor e sua prática. Papirus. 
Research, Society and Development, v. 10, n. 11, e562101120017, 2021

Fazenda, I. C. A. O papel dos estagiários nos cursos de formação de professores. In: Piconez, S. C. B. (1991). A prática de ensino e o estágio supervisionado. (19a ed.) Papirus. Pág 23-30.

Feldmann, G. (2009). Formação de Professores e escola na contemporaneidade. Editora Senac.

Ferreira, A. B. de H. (2004). Miniaurélio: o minidicionário da língua portuguesa. Positivo.

Imbernón, F. (2011). Formação Docente e profissional: formar-se para a mudança e a incerteza. Cortez.

Kenski, V. M. (1991). A vivência escolar dos estagiários e a prática de pesquisa em estágios supervisionados. In: PICONEZ, S. C. B. (coord.). A prática de ensino e o estágio supervisionado (19 . ed.). Papirus.

Kulcsar, R. (1991). O estágio supervisionado como atividade integradora. In: Piconez, S. C. B. (coord.). A prática de ensino e o estágio supervisionado $19^{\mathrm{a}}$ ed. Papirus.

Lima, T. C. \& Candido, E. C. (2014). Estágio Curricular Supervisionado: análise da experiência discente. Revista Brasileira de Enfermagem. São Paulo, Vol. 67, p. $133-140$.

Marran, A. L. \& Gomes, P. G. (2021). Estágio Curricular Supervisionado no ensino superior brasileiro: algumas reflexões. https://revistas.pucsp.br/index.php/curriculum/article/view/6785.

Marques, K. C. D. M. \& Neto, L. C. B. T. \& Brancher, V. R. (2019). Dos saberes disciplinares aos saberes pedagógicos: Desafios de iniciação à docência de estagiários em Ciências Biológicas. Revista de Educação, Ciências e Matemática. 9(3).

Oliveira, M. E. P. \& Silva, D. M. S. (2020). A coordenação pedagógica como espaço de formação continuada de professores de anos iniciais no contexto do ensino de ciências. http://dx.doi.org/10.21527/2179-1309.2020.111.203-220.

Piconez, S. C. B (1991). A prática de ensino e o estágio supervisionado. Papirus.

PImenta, S. G. A. (1997). Didática como mediação na construção da identidade do professor - uma experiência de ensino e pesquisa na Licenciatura. In: André, M. E. D. A. et al. Alternativas do ensino da didática.: Papirus, p. 37-69.

Pimenta, S. G. (org). (2005). Saberes pedagógicos e atividade docente. (4 ed.). Cortez.

Pimenta, S. G. \& Lima, M. S. L. L. (2004). Estágio e Docência. Cortez.

P.P.P. Plano Político Pedagógico (2016) Curso Normal. 10ª CRE/RS.

Shön, Donald A. (2000). Educando o profissional reflexivo: um novo design para o ensino e a aprendizagem. Artes Médicas Sul.

Tardif, M. (2012). Saberes docentes e formação profissional, Vozes.

VirOLI, S. L. M. (2021). O Estágio Curricular Supervisionado I na concepção dos discentes da Licenciatura em Química: Análise das respostas ao questionário da Supervisão do Estágio Curricular. Research, Society and Development, v. 10, n. 10 http://dx.doi.org/10.33448/rsd-v10i10.18695.

ZabALZA, M. A. (2004). O ensino universitário: seu cenário e seus protagonistas. Artmed.

Zanten, A. V. (2011). Dicionário de Educação. Vozes. 